\title{
Greater vasopressin-induced vasoconstriction and inferior effects of nitrovasodilators and milrinone in the radial artery than in the internal thoracic artery
}

Wei Wei, MDa

Cheng-Oin Yang, $\mathrm{MD}^{\mathrm{a}}$

Anthony Furnary, MDa

Guo-Wei He, MD, PhD, DSc $c^{a, b, c}$

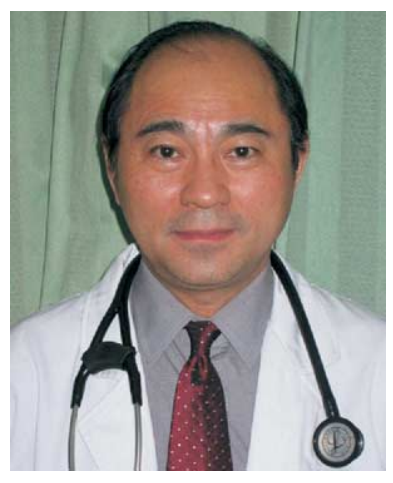

Professor He

From the Providence Heart Institute, Albert Starr Academic Center, Department of Surgery, Oregon Health and Science University, ${ }^{\text {a }}$ Portland, Ore, Division of Cardiothoracic Surgery, Department of Surgery, The Chinese University of Hong Kong, ${ }^{\text {, }}$ Hong Kong SAR, China, and Wuhan Heart Institute, The Central Hospital of Wuhan, ${ }^{\mathrm{c}}$ Wuhan, China.

This study was fully supported by the Providence St Vincent Medical Foundation, Portland, Oregon, and by grants from the Research Grants Council of the Hong Kong Special Administrative Region (Project No. CUHK4127/01M \& CUHK4383/03M), China. Dr Wei is a recipient of Starr-He International Postdoctoral Fellow, established by the Providence St Vincent Medical Foundation.

Received for publication Oct 21, 2002; revisions requested March 7, 2004; accepted for publication March 12, 2004.

Address for reprints: Guo-Wei He, MD, PhD, DSc, Department of Surgery, The Chinese University of Hong Kong, Block B, 5A, Prince of Wales Hospital, Shatin, NT, Hong Kong SAR, China (E-mail: gwhe@cuhk.edu.hk).

J Thorac Cardiovasc Surg 2005;129:33-40 $0022-5223 / \$ 30.00$

Copyright $\odot 2005$ by The American Association for Thoracic Surgery

doi:10.1016/j.jtcvs.2004.03.051
Background: Vasopressin may be a potential cause of spasm in both the radial artery and the internal thoracic artery. This study compared the vasopressin-induced contraction and the effects of milrinone, nitroglycerin, and nitroprusside in vasopressin-induced contraction between the human radial artery and the internal thoracic artery to find effective antispastic methods for arterial grafts.

Methods: Concentration-contraction (normalized as force gram produced by each millimeter of the circumference tissue of the artery) curves for vasopressin with or without pretreatment of vasodilators and concentration-relaxation curves for the vasodilators listed were established in the human radial artery $(\mathrm{n}=107)$ and internal thoracic artery $(\mathrm{n}=122)$ segments.

Results: Vasopressin induced a greater contraction in the radial artery than in the internal thoracic artery $(1.9 \pm 0.2 \mathrm{~g} / \mathrm{mm}$ vs $0.6 \pm 0.1 \mathrm{~g} / \mathrm{mm}, P<.001)$ with a higher sensitivity (lower $\mathrm{EC}_{50}$ : $-9.28 \pm 0.11$ vs $-8.91 \pm 0.05 \log _{10} \mathrm{M}, P=.006$ ). Milrinone was less potent than nitroglycerin and nitroprusside with higher $\mathrm{EC}_{50}(P$ $<.05)$ in both the internal thoracic artery and radial artery. Pretreatment with milrinone and nitroprusside significantly inhibited vasopressin contraction in the internal thoracic artery but had little effect in the radial artery. Pretreatment with nitroglycerin did not significantly inhibit the maximum vasopressin contraction in either the internal thoracic artery or radial artery.

Conclusion: The radial artery is more prone to develop spasm related to vasopressin than is the internal thoracic artery, and the effect of vasodilators in vasopressininduced contraction is different in the radial artery from that in the internal thoracic artery. A more significant prophylactic antispastic effect of milrinone and nitroprusside is demonstrated in the internal thoracic artery than in the radial artery. Therefore, more intensive antispastic treatment is necessary in the radial artery than in the internal thoracic artery during coronary artery bypass grafting.

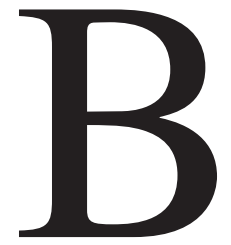

ecause of the superior results of the internal thoracic artery (ITA) in coronary artery bypass grafting $(\mathrm{CABG}),{ }^{1}$ other arterial grafts such as the radial artery (RA) have been used as coronary bypass grafts. The revival of the RA is largely based on the fact that arterial grafts have superior long-term patency to the saphenous vein, ${ }^{2}$ and the success of RA grafting is because of the improved techniques in harvesting and preservation of the vessel. ${ }^{3-6}$ Recently, a 5-year follow-up study of the RA graft showed an impressive $83 \%$ patency rate. ${ }^{5}$ However, the RA is known to have a higher incidence of spasm during harvesting. Although calcium antagonists have been used clinically to relieve RA spasm and their effect 
has been studied, ${ }^{7}$ pharmacologic prophylaxis for perioperative RA vasospasm remains a challenge because of the complexity of the cause of vasospasm.

Vasopressin (VP) is a neuropeptide that promotes reabsorption of water in renal tubular cells through V2 receptors and produces constriction of vascular smooth muscle through V1 receptors. ${ }^{8}$ VP has been regarded as one of the most potent vasoconstrictors in coronary circulation ${ }^{9}$ and is capable of sensitizing the vascular smooth muscle to the effects of norepinephrine even at low concentration. ${ }^{8}$ Similar to epinephrine and norepinephrine, which are significantly elevated during cardiopulmonary bypass, plasma VP concentration has been demonstrated to dramatically increase during cardiopulmonary bypass surgery. ${ }^{10,11}$ Even more important, the elevation of the concentration of VP is more significant during the perioperative period in patients undergoing $\mathrm{CABG}$ than in patients undergoing valve replacement. ${ }^{11}$ As reported by Philbin and colleagues, ${ }^{11} \mathrm{VP}$ (antidiuretic hormone) levels increased from a control value of $4.3 \pm 1.5 \mathrm{pg} / \mathrm{mL}$ to $13.0 \pm 3.3 \mathrm{pg} / \mathrm{mL}$ with surgical stimulation. During cardiopulmonary bypass, the VP levels increased to a peak of $23.7 \pm 3.6 \mathrm{pg} / \mathrm{mL}$ at 30 minutes and were decreasing at 45 minutes. During CABG, the concentration of VP remains dramatically high, and it gradually decreases until 2 hours after surgery.

We recently demonstrated that VP is a strong vasoconstrictor in the human ITA. ${ }^{12}$ Therefore, VP is a potential spasmogen for RA spasm in CABG. However, the VPinduced contraction has not been reported in the RA, and the interaction between VP and vasodilators in the RA is unknown.

The present study was designed to compare the contractile effect of VP in the RA and ITA. In addition, the effects of milrinone (MIL), nitroglycerin (NTG), and nitroprusside (SNP) were also studied in the VP-induced contraction in the RA and the ITA.

\section{Methods}

\section{General Techniques}

Human ITA ( $\mathrm{n}=122$ from 35 patients) and RA segments $(\mathrm{n}=$ 107 from 31 patients) were collected from the patients undergoing CABG. Approval to use discarded vessel tissues was granted by the Institutional Review Board at Providence St Vincent Hospital. The discarded artery segments were collected and placed in a container with oxygenated physiologic solution (Krebs solution) maintained at $4{ }^{\circ} \mathrm{C}$ and transferred to the laboratory immediately. The vessels were carefully cleaned of connective tissue and cut into 3-mm long rings. The rings were suspended on wires in 20-mL organ baths filled with Krebs solution maintained at $37^{\circ} \mathrm{C}$ and continuously aerated with a mixture of $95 \%$ oxygen and $5 \%$ carbon dioxide. The modified Krebs solution had the following composition (millimolar): $\mathrm{Na}^{+} 144, \mathrm{~K}^{+} 5.9, \mathrm{Ca}^{2+} 2.5, \mathrm{Mg}^{2+} 1.2$, $\mathrm{Cl}^{-}$128.7, $\mathrm{HCO}^{-} 25, \mathrm{SO}^{2-} 1.2, \mathrm{H}_{2} \mathrm{PO}_{4}{ }^{-} 1.2$, and glucose 11 .

\section{Organ Bath Techniques}

A technique that allowed for vessel rings to normalize to a physiologic pressure in the organ bath was used in this study. Artery rings were set at a pressure comparable to that in the in vivo situation. The details of the technique have been published ${ }^{13,14}$ and repeatedly used in our in vitro studies for human vessels. ${ }^{12,15,16}$ In brief, two parallel stainless-steel L-shaped wire hooks (440 $\mu \mathrm{m}$ in diameter) were introduced through the lumen of the artery ring. The lower hook was fixed to a micrometer-adjustable support leg, and the upper hook was fixed to an isometric force transducer (model FT03, Grass Instrument Company, West Warwick, RI) to record changes in isometric force, which was amplified and recorded on a polygraph chart recorder (model 79H, Grass Instrument Company). The rings were stretched up in progressive steps to determine the length-tension curve for each ring. A computer iterative fitting program (Vastand 2.1; Yang-Hui He, Princeton, $\mathrm{NJ}$ ) was used to determine the exponential line, pressure, and internal diameter. When the transmural pressure on the rings reached $100 \mathrm{~mm} \mathrm{Hg}$, as determined from their own length-tension curves, the stretch-up procedure was stopped, and the rings were released to $90 \%$ of their internal circumference at $100 \mathrm{~mm} \mathrm{Hg}$. This degree of passive tension was then maintained throughout the experiment. After the normalization procedure, the ITA or RA rings were equilibrated for at least 45 minutes.

In this study, the endothelium was intentionally preserved by cautiously dissecting and mounting the rings because endothelium plays a modulation role in the contractility and relaxation of arterial graft. We have found that this technique allows for the experiments to be performed with an intact endothelium, as determined by the functional relaxation response to acetylcholine or calcium ionophore in the human arteries. ${ }^{13,15}$

\section{Protocol}

Ring segments from the same patient were divided into 4 groups, which were randomly allocated into the 4-organ bath arrangement running concurrently.

\section{Relaxation of Vasopressin-Induced Contraction by Milrinone, Nitroglycerin, and Nitroprusside}

The $\mathrm{EC}_{10} \sim \mathrm{EC}_{90}$ of $\mathrm{VP}$ was previously determined from the logistic curve-fitting equation for ITA ${ }^{12}$ and pilot experiments for RA. VP at $-8.5 \log _{10} \mathrm{M}$ and $-9.0 \log _{10} \mathrm{M}$ induced $60 \%$ to $80 \%$ of the maximum contractile response in the ITA and RA ring segments, respectively, and these concentrations were used for precontraction of the vessels before relaxation. Cumulative concentration-relaxation curves to MIL, NTG, and SNP $\left(-10 \log _{10} \mathrm{M}-\right.$ $\left.-4.5 \log _{10} \mathrm{M}\right)$ were then established.

\section{Depression of Vasopressin-Induced Contraction by Pretreatment with Milrinone, Nitroglycerin, and Nitroprusside}

After equilibration, $\mathrm{KCl}(0.1 \mathrm{~mol} / \mathrm{L})$ was added to the organ bath, and the contraction force was recorded. The rings were then repeatedly washed with Krebs solution (at least 3 times) to restore the baseline. Subsequently, the vessels were incubated with MIL, NTG, or SNP for at least 10 minutes before the VP contraction was evoked. During the whole contraction experiments, the vasodilator was present in the bath to simulate the clinical setting under which 
the vasodilator was administrated intravenously to reach the plasma concentration we used in the bath. The contraction was expressed as the percentage of the maximum contraction force induced by $0.1 \mathrm{~mol} / \mathrm{L} \mathrm{K}^{+}$. The advantage of this expression is to normalize the contraction by the response to a standard vasoconstrictor to eliminate the possible differences caused by other factors. To be sure of the validity of the comparison among the arteries treated with different concentrations of the vasodilator, each artery was cut into 3 (for MIL study) or 4 (for SNP and NTG studies) rings, allocated for each treatment. There was always 1 ring taken from the same segment of the vessel that was set as the control for the rings treated with vasodilators to eliminate the possible influence by other factors.

The concentration of MIL $\left(-5.15 \log _{10} \mathrm{M}\right)$ and NTG (-7 $\log _{10} \mathrm{M}$ ) for the pretreatment was similar to the optimum therapeutic free plasma concentration reached clinically. ${ }^{17,18}$ Therapeutic free plasma concentration of SNP was not available; therefore, the same concentration used for NTG was chosen for the study. The supraclinical concentrations were also studied because these concentrations could be reached topically during CABG.

\section{Data Analysis}

The sensitivity of both vasoconstrictor and vasodilator substances was expressed as $\mathrm{EC}_{50}$, the effective concentration that caused $50 \%$ of maximal contraction or relaxation. The $\mathrm{EC}_{50}$ was determined from each concentration-contraction (or relaxation) curve by a logistic, curve-fitting equation: $\mathrm{E}=\mathrm{MA}^{\mathrm{P}} /\left(\mathrm{A}^{\mathrm{P}}+\mathrm{K}^{\mathrm{P}}\right)$ where $\mathrm{E}$ is response, $\mathrm{M}$ is maximal contraction or relaxation, $\mathrm{A}$ is concentration, $\mathrm{K}$ is $\mathrm{EC}_{50}$ concentration, and $\mathrm{P}$ is the slope parameter. ${ }^{13} \mathrm{~A}$ computerized program was used for the curve fitting.

All results were expressed as mean $\pm \mathrm{SEM}$. The data were analyzed by analysis of variance (ANOVA) and Dunnett's post hoc comparison ${ }^{19}$ for comparing several treatment groups with a control and by unpaired $t$ test for comparing between 2 independent groups.

In this study, "sensitivity" is used to describe the location of the concentration-response curve and is measured by the $\mathrm{EC}_{50}$ value; "reactivity" describes the range of response and is measured as the maximum relaxation or contraction.

\section{Drugs}

NTG and SNP were purchased from Abbott Laboratories (Chicago, Ill). MIL was generously provided as a gift by SterlingWinthrop Pharmaceutical Research Division (Rensselear, NY). Arginine VP was ordered from Sigma Chemical Co (St Louis, Mo).

\section{Results}

\section{Vasopressin-Induced Contraction in the Internal Thoracic Artery and Radial Artery}

The diameter at a pressure of $100 \mathrm{~mm} \mathrm{Hg}$ (D100) was 3.01 $\pm 0.05 \mathrm{~mm}$ for the RA and $2.6 \pm 0.04 \mathrm{~mm}$ for the ITA $(P$ $<$.001). VP invoked a stronger contraction force in the RA than in the ITA (maximal contraction: $16.4 \pm 1.2 \mathrm{~g}, \mathrm{n}=17$ vs $5.0 \pm 0.7 \mathrm{~g}, \mathrm{n}=25 ; P<.001$, Figure $1, b$ ). Moreover, when normalized as force gram produced by each millimeter of the circumference tissue of the artery, the contraction
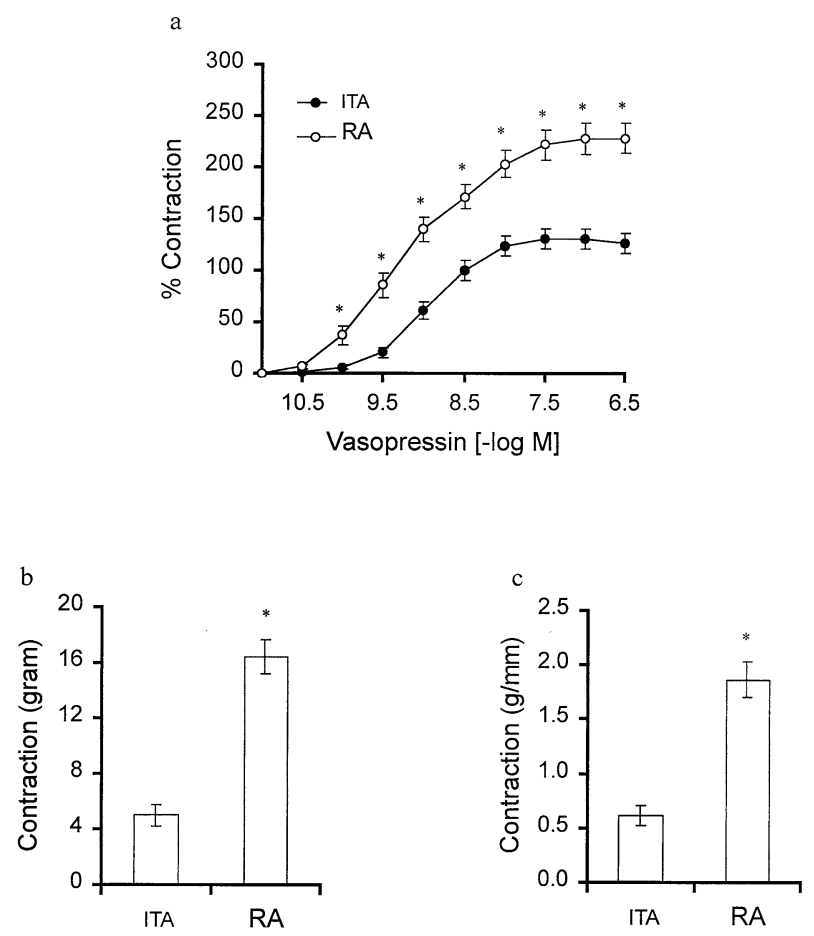

Figure 1. a, Mean concentration-contraction (percentage of 0.1 $\mathrm{mol} / \mathrm{L} \mathrm{K}^{+}$-induced contraction) curves for VP in the ITA $(n=25)$ and RA ( $n=17$ ). $b$, Maximal contraction force (gram). c, Maximal contraction normalized as force gram per each millimeter of the circumference of the artery $(\mathrm{gram} / \mathrm{mm})$. Data are shown as mean $\pm S E$ ( $P<.001$, unpaired $t$ test). ITA, Internal thoracic artery; $R A$, radial artery.

(gram/millimeter) was still significantly greater in the RA than in the ITA $(1.8 \pm 0.2 \mathrm{~g} / \mathrm{mm}$ vs $0.6 \pm 0.1 \mathrm{~g} / \mathrm{mm}, P<$ $.001)$. The $\mathrm{EC}_{50}$ was significantly lower in the RA than in the ITA $\left(-9.28 \pm 0.11 \mathrm{vs}-8.91 \pm 0.05 \log _{10} \mathrm{M}, P=.006\right)$ (Figure 1), and this reveals higher sensitivity of the RA to VP.

\section{Relaxation of Vasopressin-Induced Contraction by Milrinone, Nitroglycerin, and Nitroprusside}

In the ITA, the maximum relaxation caused by MIL, NTG, and SNP was $96.2 \% \pm 2.0 \%, 92.6 \% \pm 2.8 \%$, and $91.2 \% \pm$ $3.8 \%$, respectively $(P=.7 \sim 1.0$; Figure 2$)$. The $\mathrm{EC}_{50}$ for NTG $\left(-7.40 \pm 0.12 \log _{10} \mathrm{M}\right)$ was lower than that for SNP $\left(-6.51 \pm 0.16 \log _{10} \mathrm{M}, 95 \%\right.$ confidence interval [CI]: 0.74$1.64, P<.001)$ and MIL $\left(-6.21 \pm 0.12 \log _{10} \mathrm{M}, 95 \% \mathrm{CI}\right.$ : $0.44-1.34, P<.001$ ), indicating that the sensitivity of the vessel to NTG is the highest among the 3 vasodilators.

In the RA, the maximum relaxation caused by MIL $(73.7 \% \pm 3.4 \%)$ was significantly less than that of NTG $(95.1 \% \pm 1.6 \%, 95 \%$ CI: 3.47-31.7, $P=.02)$ and SNP $98.6 \% \pm 0.7 \%, 95 \%$ CI: $2.56-29.5, P=.02)$. The $\mathrm{EC}_{50}$ for MIL ( $\left.-5.44 \pm 0.07 \log _{10} \mathrm{M}\right)$ was higher than that for 

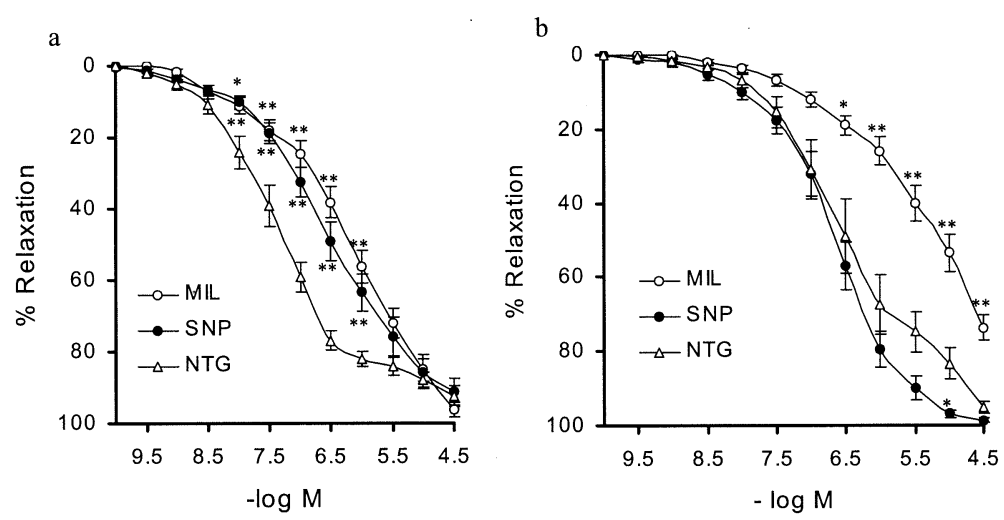

Figure 2. Mean concentration-response (percentage of reversal of VP contraction) curves for MIL, SNP, and NTG in the ITA (a, $n=10$ in each group) and $R A\left(b, n=9\right.$ in each group). Data are shown as mean $\pm S E\left({ }^{*} P<.05\right.$, ${ }^{* *} P<.01$ vs NTG, 1-way ANOVA). MIL, Milrinone; SNP, nitroprusside; NTG, nitroglycerin.

NTG $\left(-6.48 \pm 0.22 \log _{10} \mathrm{M}, 95 \% \mathrm{CI}:-1.67-0.37, P=\right.$ $.003)$ and SNP $\left(-6.60 \pm 0.14 \log _{10} \mathrm{M}, 95 \% \mathrm{CI}:-1.77\right.$ $0.47, P=.001$; Figure 2), also indicating the decreased sensitivity of the vessel to MIL compared with the other 2 vasodilators.

\section{Depression of Contraction to Vasopressin by Pretreatment with Milrinone, Nitroglycerin, and Nitroprusside}

Effect of milrinone. In the ITA, pretreatment with MIL at $-5.15 \log _{10} \mathrm{M}$ and $-4.15 \log _{10} \mathrm{M}$ significantly inhibited VP contraction $(P<.001$ vs the control, 2-way ANOVA) (Figure 3 and Table 1). Pretreatment of MIL $\left(-4.15 \log _{10} \mathrm{M}\right.$ and $\left.-5.15 \log _{10} \mathrm{M}\right)$ significantly inhibited the maximum contraction to VP $(36.2 \% \pm 7.6 \%, P<.001$ and $73.2 \% \pm$ $14.5 \%, P<.001$ vs $119.3 \% \pm 13.1 \%$ in the control) (Figure $3, a)$. In contrast, in the RA, MIL did not significantly change the maximum contraction to $\mathrm{VP}(P=.85 \sim .96$, Figure $3, b)$. In regard to the $\mathrm{EC}_{50}$, MIL $\left(-4.15 \log _{10} \mathrm{M}\right)$ significantly decreased the sensitivity (increased $\mathrm{EC}_{50}$ ) for the VP contraction in the ITA and RA compared with the control (Figure 3 and Table 1).

Effect of nitroprusside. In the ITA, pretreatment with SNP at $-6 \log _{10} \mathrm{M}(P=.008)$ and $-4.5 \log _{10} \mathrm{M}(P=.01)$ significantly inhibited VP-induced contraction versus the control (2-way ANOVA, Figure 4 and Table 1). SNP (-6 and $\left.-4.5 \log _{10} \mathrm{M}\right)$ significantly reduced the maximum contraction by VP $(47.6 \% \pm 8.8 \%, P=.006$ and $54.8 \% \pm$ $17.3 \%, P=.02$ vs $114.3 \% \pm 13.6 \%$ in the control). In contrast, SNP did not significantly reduce the maximum contraction to VP in the RA compared with the control $(P=$ $.4 \sim 1.0)$. In addition, SNP did not significantly change the $\mathrm{EC}_{50}$ for the VP contraction in either the ITA or RA $(P=$ $.4 \sim 1.0$, Table 1). However, at the lower concentration of VP $\left(-10.5--9 \log _{10} \mathrm{M}\right)$, SNP at -6 and $-4.5 \log _{10} \mathrm{M}$ significantly inhibited the contraction in the RA compared with the control $(P=.02 \sim .005)$ (Figure 4$)$.

Effect of nitroglycerin. Pretreatment with NTG did not significantly inhibit the maximum contraction induced by VP in either the ITA or the RA $(P=.4 \sim .98$, Figure 5 and Table 2). However, NTG significantly increased the $\mathrm{EC}_{50}$ for the VP contraction in the ITA compared with the control $(P=.02)$. In contrast, in the RA, the $\mathrm{EC}_{50}$ was not significantly different among the groups $(P=.6 \sim 1.0)$. At lower concentrations of VP $\left(-10.5--9.5 \log _{10} \mathrm{M}\right)$, pretreatment with NTG at -6 and $-4.5 \log _{10} \mathrm{M}$ significantly inhibited the contraction compared with the control $(P=.03 \sim .002)$ (Figure 5 and Table 1).

\section{Discussion}

This study demonstrated the following: (1) The RA is more sensitive and develops a stronger contraction to VP than the ITA; (2) MIL is effective in both reversing and preventing the VP contraction in the ITA, but in the RA either its relaxation or its effect in prevention of VP contraction is limited; (3) SNP and NTG may act differently in preventing the VP contraction in the ITA: SNP significantly depressed the maximum contraction, whereas NTG only significantly reduced the sensitivity; and (4) both NTG and SNP effectively reverse the VP contraction in the RA but had little effect on prophylaxis.

Similar to the ITA, the RA has recently been reported to have superior long-term patency ${ }^{5}$ to the saphenous vein. ${ }^{1}$ However, the use of the RA is compromised by its relatively higher incidence of vasospasm.,3,15 Further, the 5-year patency rate of the RA $(83 \%)$ is less than that of the ITA $(91 \%),{ }^{5}$ and this may indicate that further improvement of the method to control vasospasm in the RA is necessary.

In the present study, the RA was found to have a larger diameter than the ITA, which is favorable for its use in 
a

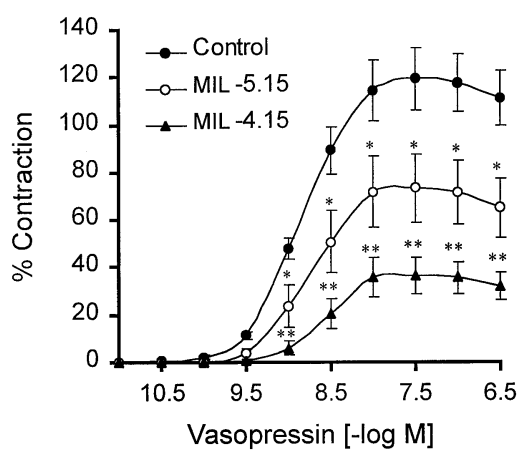

b

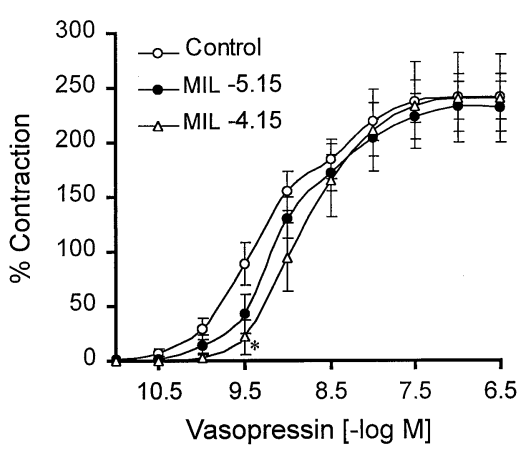

Figure 3. Mean concentration-contraction (percentage of $0.1 \mathrm{~mol} / \mathrm{L} \mathrm{K}^{+}$-induced contraction) curves for VP in the ITA ( $a, n=8$ in each group) and RA (b, $n=8$ in each group) with or without pretreatment of MIL ( $\log M$ concentration). Data are shown as mean $\pm \mathrm{SE}\left({ }^{*} P<.05,{ }^{* *} P<.001\right.$ vs the control; 1 -way ANOVA). MIL, Milrinone.

TABLE 1. Inhibitory effect of MIL, SNP, and NTG on maximal contraction (percentage of the $0.1 \mathrm{~mol} / \mathrm{L} \mathrm{K}^{+}$-induced contraction force) and $\mathrm{EC}_{50}$ of VP-induced contraction in the ITA and RA

\begin{tabular}{|c|c|c|c|c|c|c|c|c|}
\hline \multicolumn{5}{|c|}{ ITA } & \multicolumn{4}{|c|}{$\mathbf{R A}$} \\
\hline $\log _{10} M$ & $\begin{array}{c}\text { Maximal } \\
\text { contraction } \\
(\%)\end{array}$ & $P$ value & $\begin{array}{c}E C_{50} \\
\left(-\log _{10} M\right)\end{array}$ & $P$ value & $\begin{array}{c}\text { Maximal } \\
\text { contraction } \\
(\%)\end{array}$ & $P$ value & $\begin{array}{c}E_{50} \\
\left(-\log _{10} M\right)\end{array}$ & $P$ value \\
\hline MIL (n = 8) & & .000 & & .001 & & .97 & & .005 \\
\hline Control & $119.3 \pm 13.1$ & & $8.88 \pm 0.04$ & & $242.0 \pm 20.6$ & & $9.26 \pm 0.09$ & \\
\hline-5.15 & $73.2 \pm 14.5^{*}$ & & $8.74 \pm 0.05$ & & $234.2 \pm 22.6$ & & $9.04 \pm 0.09$ & \\
\hline-4.15 & $36.2 \pm 7.6^{* *}$ & & $8.55 \pm 0.06^{* *}$ & & $242.8 \pm 40.6$ & & $8.77 \pm 0.11^{* *}$ & \\
\hline $\operatorname{SNP}(n=8)$ & & .005 & & .2 & & .53 & & .1 \\
\hline Control & $114.3 \pm 13.6$ & & $8.79 \pm 0.07$ & & $228.7 \pm 19.8$ & & $9.26 \pm 0.21$ & \\
\hline-7 & $100.4 \pm 16.5$ & & $8.67 \pm 0.12$ & & $226.2 \pm 26.0$ & & $9.21 \pm 0.16$ & \\
\hline-6 & $47.6 \pm 8.8^{* *}$ & & $8.66 \pm 0.06$ & & $201.1 \pm 20.6$ & & $8.89 \pm 0.12$ & \\
\hline-4.5 & $54.8 \pm 17.3^{*}$ & & $8.52 \pm 0.09$ & & $190.3 \pm 20.3$ & & $8.75 \pm 0.14$ & \\
\hline NTG $(n=9)$ & & .57 & & .015 & & .94 & & .17 \\
\hline Control & $155.4 \pm 20.3$ & & $9.04 \pm 0.09$ & & $226.3 \pm 21.7$ & & $9.27 \pm 0.22$ & \\
\hline-7 & $116.4 \pm 17.3$ & & $8.75 \pm 0.05^{*}$ & & $221.5 \pm 22.9$ & & $8.96 \pm 0.15$ & \\
\hline-6 & $108.6 \pm 28.2$ & & $8.76 \pm 0.06^{*}$ & & $204.9 \pm 16.5$ & & $9.02 \pm 0.14$ & \\
\hline-4.5 & $124.4 \pm 29.5$ & & $8.76 \pm 0.07^{*}$ & & $214.0 \pm 35.6$ & & $8.73 \pm 0.14$ & \\
\hline
\end{tabular}

$V P$, Vasopressin; MIL, milrinone; SNP, nitroprusside; NTG, nitroglycerin; ITA, internal thoracic artery; $R A$, radial artery; ANOVA, analysis of variance.

$P$ values are compared among the groups; ${ }^{*} P<.05 ;{ }^{*} P<.01$ vs the control (1-way ANOVA).

CABG. However, the RA presents a significantly stronger and more sensitive (lower $\mathrm{EC}_{50}$ ) contractile response to VP than the ITA (Figure 1). These results are in accordance with our previous study, ${ }^{15}$ as well as with another study, ${ }^{6}$ in which the RA has higher receptor-mediated contractility compared with the ITA. It has been demonstrated that there is higher density of smooth muscle cells in the media of the RA wall compared with the ITA, ${ }^{20,21}$ and the stronger VP-induced contraction in the RA may be related to this anatomic feature. Moreover, the myocytes are organized into multiple tight layers in the RA, whereas the muscle cells are less organized and loose in shape in the ITA. ${ }^{21}$ Another possibility is that the density of the VP receptors in the RA may be different than that in the ITA. The signifi- cantly increased plasma level of VP during CABG indicates that VP may be a potential risk factor leading to vasospasm of the RA in CABG perioperatively.

As a phosphodiesterase inhibitor, MIL is a noncatecholamine, nonglycosidic inotropic agent with vasodilator activity. ${ }^{22}$ Cardiac contraction and vascular smooth muscle relaxation are related to the biologic activity of second messengers such as cyclic adenosine monophosphate and cyclic guanosine monophosphate, which are hydrolyzed by phosphodiesterases. ${ }^{23}$ The positive inotropic and vasodilator effect of phosphodiesterase inhibitors may therefore be particularly indicated in patients during CABG. ${ }^{24-26}$ Therefore we have systematically studied the role of MIL in the human coronary bypass conduits, ${ }^{24-26}$ including the RA. ${ }^{26}$ 

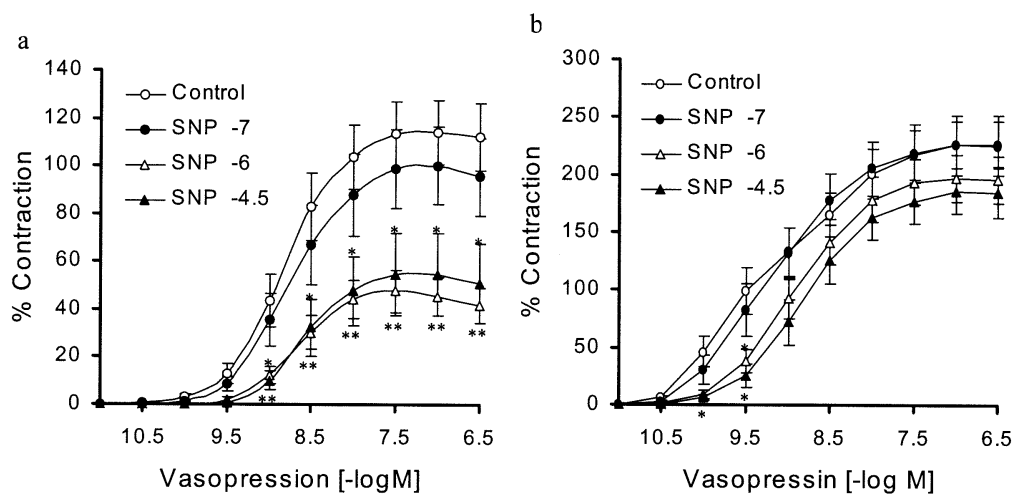

Figure 4. Mean concentration-contraction (percentage of $0.1 \mathrm{~mol} / \mathrm{L} \mathrm{K}^{+}$-induced contraction) curves for VP in the ITA ( $a, n=8$ in each group) and RA (b, $n=7$ in each group) with or without pretreatment of SNP (Iog M concentration). Data are shown as mean \pm SE $\left({ }^{*} P<.05,{ }^{* *} P<.01\right.$ vs the control; 1-way ANOVA). SNP, Nitroprusside.
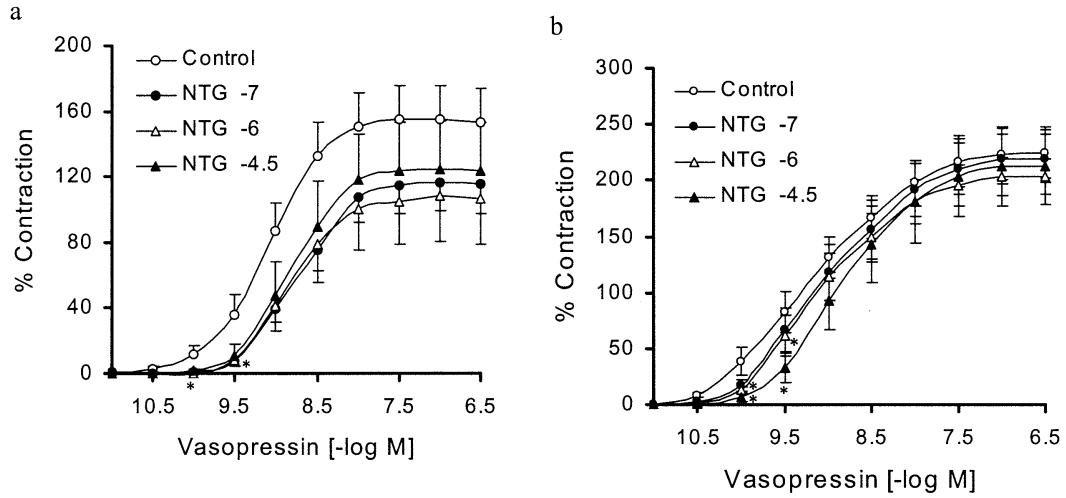

Figure 5. Mean concentration-contraction (percentage of $0.1 \mathrm{~mol} / \mathrm{L} \mathrm{K}^{+}$-induced contraction) curves for VP in the ITA ( $a, n=9$ in each group) and RA (b, $n=7$ in each group) with or without pretreatment of NTG ( $\log M$ concentration). Data are shown as mean $\pm S E\left({ }^{*} P<.05\right.$ vs the control; 1-way ANOVA). NTG, Nitroglycerin.

In the present study, it was found that MIL had a superior effect in the ITA than in the RA. MIL induced a full relaxation in the ITA but had only a submaximal effect in the RA (Figures 2 and 3). This shows that MIL has a vessel-selective effect. Further, regarding the prevention of the VP-induced contraction, MIL had a significant effect in the ITA but only little effect in the RA. This further shows the vessel-selective effect of MIL.

Notably, even in the same artery (in both the ITA and RA), the effect of MIL on the VP-induced vasoconstriction is different between the relaxation and the prevention of the relaxation. At the concentration of $-4.5 \log$ M, MIL induced $100 \%$ relaxation in the ITA (Figure 2,a), but when it is used before the contraction to VP at an even higher concentration $(-4.15 \log \mathrm{M})$, the ITA can still contract to approximately $40 \%$ of the maximum contraction (Figure 3, a). This phenomenon is more significant in the RA, in which the maximum contraction to VP was not affected by the pretreatment of MIL, although the "sensitivity" to VP was increased by the pretreatment (Table 1 and Figure $3, b$ ).

In previous studies, we have found that vasodilators such as $\mathrm{MIL}^{25,26}$ and $\mathrm{NTG}^{27}$ are potent in reversing existing vascular contraction but less effective if applied before the contraction. As described by Maurice and colleagues, ${ }^{28}$ there may be critical differences in the state of the vascular smooth muscle before and after induction of contraction that affect the responses to vasodilator substances. Increases in intracellular $\mathrm{Ca}^{2+}$ concentration and the phosphorylation of myosin light chain are important in the contraction of vascular smooth muscle ${ }^{29}$; therefore, compounds that block these processes will inhibit contraction. However, relaxation of smooth muscle that involves reversal of a latch state is less dependent on the inhibition of $\mathrm{Ca}^{2+}$ mobilization or on dephosphorylation of myosin. ${ }^{30}$

In the present study it was also observed that, to some extent, NTG and SNP acted differently against VP-mediated 
contraction in the ITA. Although both NTG and SNP had an almost full relaxation in VP-mediated contraction in the ITA, when used before the contraction (pretreatment) SNP significantly inhibited the maximum VP-induced contraction with little effect on $\mathrm{EC}_{50}$. In contrast, NTG significantly reduced the sensitivity to VP (increased $\mathrm{EC}_{50}$ ) without reducing the maximum contraction (Table 2 and Figures 4 and 5). These findings are in agreement with previous studies. ${ }^{7,24}$ In addition to the aforementioned mechanisms, this could be explained by the rapidly developed NTG tolerance (tachyphylaxis), ${ }^{24,27,31}$ whereas the inhibitory effect of SNP is only marginally suppressed in arteries that tolerate NTG. ${ }^{32}$ Further, with regard to the decreased potency in preventing contraction by NTG, another possible reason could be that NTG is a short-lived drug. After a 10-minute incubation, although the intention was to keep the drug in the bath, it is unknown what concentration of NTG was left in the bath and what percentage of NTG was metabolized.

On the other hand, both NTG and SNP had a similar relaxant effect in the RA compared with the ITA but a limited effect in inhibiting VP-induced contraction, further demonstrating the differences between the RA and ITA.

\section{Conclusion}

The present study demonstrates that the RA has greater (VP) receptor-mediated contractility than the ITA and is more prone to vasospasm mediated by VP. Both MIL and nitrovasodilators may effectively reverse the VP-mediated contraction in both the ITA and RA. MIL and SNP may be used for prophylaxis against VP-induced contraction in the ITA, but they have limited effect in the RA. This study emphasizes more intensive treatment against VP-mediated vasospasm in the RA during CABG.

The technical assistance by Drs A. Starr, H. Storm, J. Swanson, A. Ahmad, H. Gately, M. Savitt, and Kay McCantz and other nurses in the cardiac operating room at Providence St Vincent Hospital is gratefully acknowledged.

\section{References}

1. Loop FD, Lytle BW, Cosgrove DM, et al. Influence of the internalmammary-artery graft on 10-year survival and other cardiac events. N Engl J Med. 1986;314:1-6.

2. Acar C, Jebara VA, Portoghese M, et al. Revival of the radial artery for coronary artery bypass grafting. Ann Thorac Surg. 1992;54:652-9.

3. He GW, Yang CQ. Use of verapamil and nitroglycerin solution in preparation of radial artery for coronary grafting. Ann Thorac Surg. 1996;61:610-4.

4. He GW. Verapamil plus nitroglycerin solution maximally preserves endothelial function of the radial artery: comparison with papaverine solution. J Thorac Cardiovasc Surg. 1998;115:1321-7.

5. Acar C, Ramsheyi A, Pagny JY, et al. The radial artery for coronary artery bypass grafting: clinical and angiographic results at five years. J Thorac Cardiovasc Surg. 1998;116:981-9.

6. Chardigny C, Jebara VA, Acar C, et al. Vasoreactivity of the radial artery. Comparison with the internal mammary and gastroepiploic arteries with implications for coronary artery surgery. Circulation. 1993;88(5 Pt 2):II115-27.
7. He GW, Yang CQ. Comparative study on calcium channel antagonists in the human radial artery: clinical implications. J Thorac Cardiovasc Surg. 2000;119:94-100.

8. Medina P, Acuna A, Martinez-Leon JB, et al. Arginine vasopressin enhances sympathetic constriction through the $\mathrm{V} 1$ vasopressin receptor in human saphenous vein. Circulation. 1998;97:865-70.

9. Maturi MF, Martin SE, Markle D, et al. Coronary vasoconstriction induced by vasopressin. Production of myocardial ischemia in dogs by constriction of nondiseased small vessels. Circulation. 1991;83:211121.

10. Wu W, Zbuzek VK, Bellevue C. Vasopressin release during cardiac operation. J Thorac Cardiovasc Surg. 1980;79:83-90.

11. Philbin DM, Coggins CH, Wilson N, et al. Antidiuretic hormone levels during cardiopulmonary bypass. J Thorac Cardiovasc Surg. 1977;73: 145-8.

12. Wei W, Floten HS, He GW. Interaction between vasodilators and vasopressin in internal mammary artery and clinical significance. Ann Thorac Surg. 2002;73:516-22.

13. He GW, Angus JA, Rosenfeldt FL. Reactivity of the canine isolated internal mammary artery, saphenous vein, and coronary artery to constrictor and dilator substances: relevance to coronary bypass graft surgery. J Cardiovasc Pharmacol. 1988;12:12-22.

14. He GW, Rosenfeldt FL, Buxton BF, Angus JA. Reactivity of human isolated internal mammary artery to constrictor and dilator agents. Implications for treatment of internal mammary artery spasm. Circulation. 1989;80(3 Pt 1):I141-50.

15. He GW, Yang CQ. Radial artery has higher receptor-mediated contractility but similar endothelial function compared with mammary artery. Ann Thorac Surg. 1997;63:1346-52.

16. He GW, Yang CQ. Vasorelaxant effect of phosphodiesterase-inhibitor milrinone in the human radial artery used as coronary bypass graft. J Thorac Cardiovasc Surg. 2000;119:1039-45.

17. Wei JY, Reid PR. Quantitative determination of trinitroglycerin in human plasma. Circulation. 1979;59:588-92.

18. Pagni ED, Buchholz RA, Silver PJ. Cardiovascular cyclic nucleotide phosphodiesterases and their role in regulating cardiovascular function. In: Hasenfuss G, Holubarsch C, Just H, Alpert NR, editors. Cellular and molecular alterations in the failing heart. Darnstadt: Steinkopff Verlag; 1992. p. 73-86.

19. Dunnett CW. A multiple comparison procedure for comparing several treatment with a control. J Am Stat Assoc. 1955;50:1096-121.

20. van Son JAM, Smedts F, Vincent JG, Van Lier HJ, Kubat K. Comparative anatomic studies of various arterial conduits for myocardial revascularization. J Thorac Cardiovasc Surg. 1990;99:703-7.

21. Acar C, Jebara VA, Portoghese M, et al. Comparative anatomy and histology of the radial artery and the internal thoracic artery. Implication for coronary artery bypass. Surg Radiol Anat. 1991;13:283-8.

22. Baim DS, McDowell AV, Cherniles J, et al. Evaluation of a new bipyridine inotropic agent-milrinone-in patients with severe congestive heart failure. $N$ Engl J Med. 1983;309(13):748-56.

23. Silver PJ, Lepore RE, O'Connor B, et al. Inhibition of the low $\mathrm{Km}$ cyclic AMP phosphodiesterase and activation of the cyclic AMP system in vascular smooth muscle by milrinone. J Pharmacol Exp Ther. 1988;247:34-42.

24. He GW, Yang CQ. Comparison of nitroprusside and nitroglycerin in inhibition of angiotensin II and other vasoconstrictor-mediated contraction in human coronary bypass conduits. Br J Clin Pharmacol. 1997;44:361-7.

25. He G-W, Yang C-Q. Inhibition of vasoconstriction by phosphodiesterase III inhibitor milrinone in human conduit arteries used as coronary bypass grafts. J Cardiovasc Pharmacol. 1996;28:208-14.

26. He G-W, Yang C-Q. Vasorelaxant effect of phosphodiesterase-inhibitor milrinone in the human radial artery used as coronary bypass graft. J Thorac Cardiovasc Surg. 2000;119:1039-45.

27. He G-W, Buxton B, Rosenfeldt F, Angus JA. Reactivity of human isolated internal mammary artery to constrictor and dilator agents. Implications for treatment of internal mammary artery spasm. Circulation. 1989;80(Suppl):I-141-50.

28. Maurice DH, Crankshaw D, Haslam RJ. Synergistic actions of nitrovasodilators and isoprenaline on rat aortic smooth muscle. Eur J Pharmacol. 1991;192:235-42. 
29. Murphy RA. Contraction in smooth muscle cells. Annu Rev Physiol. 1989;51:275.

30. Hai CM, Murphy RA. Cross-bridge phosphorylation and regulation of latch state in smooth muscle. Am J Physiol. 1988;254:C99.

31. Sage PR, de la Lande IS, Stafford I, et al. Nitroglycerin tolerance in human vessels: evidence for impaired nitroglycerin bioconversion. Circulation. 2000;102:2810-5.

32. Matsumoto T, Takahashi M, Nakae I, et al. Vasorelaxing effect of S-nitrosocaptopril on dog coronary arteries: no cross-tolerance with nitroglycerin. J Pharmacol Exp Ther. 1995;275:1247-53.

\section{JTCVS On-Line Manuscript Submission and Review Please visit http://www.editorialmanager.com/jtcvs/}

Effective September 15, 2001, authors and reviewers may submit manuscripts and reviews electronically via Editorial Manager, our new Web-based system with full electronic submission, review, and status update capabilities.

As we move from paper to electronic submissions, the Editorial Office will make proxy submissions of all manuscripts accompanied by a diskette containing the electronic files of the text, tables, and figures. Editors, authors, and reviewers will receive automatic e-mails when significant events occur.

We strongly encourage all authors and reviewers to use Editorial Manager. Although we will continue to accommodate the submission of paper manuscripts for some months, our goal is to be completely electronic within 9 to 12 months.

All individuals currently in our database for whom we have e-mail addresses will receive via e-mail a system-assigned username and password that can be used to log in to the system without prior registration. All those not receiving the e-mail must register the first time they use the system.

As with any broad systemic change, the conversion to the new system will take some time to complete. We ask your patience as we replace our in-office database with the new system. We also encourage you to take advantage of the speed and efficiency that the new system will provide for us all: editor, author, reviewer, and publisher. 